\title{
Impact Analysis of Valve Clearances Adjustment in Output of Pollutant Gaseous Products: A Case Study in few Automative Spark- ignition Engines \\ Abstract
}

\section{Motamedi Navid', Jafarmadar Samad ${ }^{2}$}

${ }^{1}$ Department of Mechanical Engineering, Jolfa International Branch, Islamic Azad University, Jolfa, Iran

${ }^{2}$ Department of Mechanical Engineering, Urmia Branch, Islamic Azad University, Urmia, Iran

Study Area: Bandar Abbas, Iran

Coordinates: $27^{\circ} 11^{\prime} \mathrm{N} ; 56^{\circ} 16^{\prime} \mathrm{E}$

Key words: Emissions, Automotive timing, Filler valve
Areas having the highest number of automotive and factories, the air pollution levels in such places are usually high. Vehicles are the major sources of air pollution, it increases the amount of gas, soot and dust in the air which damage the human health. Automotive carbon monoxide and sulfur dioxide from vehicle exhaust from the combustion of coal mixes in the air. Further, the primary pollutants undergo chemical reactions which ultimately create more contaminants. For the prevention of air pollution in nowadays in many countries several companies are manufacturing electric and hybrid vehicles the smart way to prevent smoke from vehicle emissions. In the present piece of work we have tried to understand that how to deal with the filler valve screw Experimental Methods i.e., the filler valve to adjust the amount of pollutants, the impact of gasoline engine exhaust products, and Pride has been studied and tested for this purpose in a different setting emission gasoline engine filler peated and data extraction were compared and examined.

\section{Introduction:}

Automotive is a series of various designed parts which are arranged regularly in a way to achieve the considered goal. Fuel consumption causes the production of various gases which have been exerted from automotive exhaust and emitted into the ambient atmosphere. High fuel consumption by motor vehicles is reducing globally the fossil fuel resources and creating high pollution in the environment. As per an estimation, the amount of automotive carbon dioxide and other pollutants in the environment by 2050 will be twice their amount as it was in 2005. Hence, by evaluating the high cost of existing catalysts and day by day increment of the environmental pollutants, attention has been made to required changes in the structure of such combustion engines to prevent and optimise production of relevant pollutant gases. One of the most suitable ways to optimise gases outlet in the structure of engine can be an effort to modify the valve clearances adjustment (Heywood, 1988). History of internal combustion engines dates back to 1876 that Nikolaus Otto built the first engine spark. This engine worked with maximum efficiency of $11 \%$ as it was overweight. Otto has increased the efficiency to $14 \%$ by proposing a four-stroke performance cycle and reduced besides reducing the engine volume (Stone, 1999). Further, by the late 19th century other engines were invented and concluded that Compression ratio exerts a direct effect on engine efficiency, but it failed due to the problem of engine knocking. During the year 188 os, under automotive burst or and ignition system product development, the speed of engines had increased and the possibility to use the engine in automotive was facilitated. In 1892, a German engineer named Rudolf Diesel patented a new type of engine in which at Compression Stroke the air was compressed and at the end of this stroke Liquid fuel was sprayed into the hot air. Since air does not undergo knocking, the air enabled to raise the compression and increase the engine efficiency to a double extent. One of the other patterns of an engine was the rotational engine by Felix Wankel in 1957. Fuels have a great impact on engine development. The first engines produced mechanical power by burning gas. In the late nineteenth century, gasoline was started to use as automotive buretor. The initial gasoline was quite volatile and therefore the possibility to increase the compression ratio was not more than four but the motor launch (start) was comfortable. William Burton was able to produce a gasoline to meet the weight to less than one-third of the previous state

*Corresponding Author: navid.motamadi@gmail.com 
increasing demands of gasoline.

Due to high boiling point, however starting of such engine at cold state was quite difficult which was further solved by inventing electric starter in 1912. Anti- knock effect was discovered in 1930 by General Motors and by the year 1930 using catalysts caused producing high-quality gasoline (Lee et al., 2010). The problem of air pollution mainly came forward in the year1940s in Los Angeles and Smog problem due to the reaction between nitrogen oxides and hydroautomotive carbons in the presence of sunlight was understood in 1952 . Therefore, to protect the environment in developing countries, some standards were proposed in the context of restricting emissions from the engines. Further the equipment such as catalytic converters were used in engine and the additives to improve fuel quality and remove lead were used in fuel. Since the 1970 , due to rising prices of petroleum products and to reduce fuel consumption of the engine, great efforts were made to raise efficiency (Kramer \& Phlips, 2002). Many attempts have been made to produce alternative fuels of gasoline and diesel, methanol and ethanol. Hydrogen, synthetic gasoline and diesel derived from petroleum and coal stones are considered long-term alternatives. After over one century, it was considered that the engines have reached its maximum limit of development, but practically engines reach higher eff iciency and power with lower pollution which is mainly due to the reduction in weight, price and heat loss. Fuel injection is indeed one of the modern and hightechnological concepts which using it is a prerequisite if we intend to have the highest efficiency. But the fuel injection which has been used for decades and has been the standard method for delivery of fuel to engine before World War II. With a brief review of the role of vehicles especially their fuel system, we perceive their important and signif icant contribution to air pollution, especially in large cities. After proper knowledge about the pollutants which emit to humans' environment, the necessity to modify vehicles and fuel system could be perceived.

Fuel systems injection is targeted for optimising the fuel consumption which reduces exhaust emissions (Moro et al., 2001). Fuel in most of the vehicles is from fossil source which pollutes the air while burning. To reduce emissions from combustion engines, it is better to replace liquefied petroleum gas with fossil fuels and/or modify fuel system, for which important provisions have been made including improvement of the quality of automotive carburetors to use of electronic fuel injection (Roberts \& Stanglmaier, 1999).

Filergiri: in a number of engines, filergiri takes place via adjustment shim which should have been produced from high-grade steel. In the case of using the parts with inappropriate dimensional accuracy, Filergiri conditions will not be precise and if the parts with low quality are used, contact of the valve might be leaked after a while due to the high thermal stress and multiple impacts, whereby the automotive would exert from suitable filergiri conditions. Low noise valve, reducing engine efficiency and power, increasing fuel consumption with increasing emissions refer to signs of valve mal-adjustment and inappropriate function conditions of valves for which proper attempt for proper filergiri is needed (Cairns et al., 2006).

Table 1. Valve clearances adjustment systems

\begin{tabular}{cl}
\hline Automatic & Manual \\
\hline use of hydraulic tappet (self-adjusting) & Filergiri \\
\hline
\end{tabular}

In engine adjustment, filergiri has been recognised as the most sensitive stage of procedure for increasing efficiency, decreasing fuel consumption and the amount of pollutants emission (Allen \& Law, 2001). In case of using the parts with inappropriate dimensional accuracy, filergiri conditions would not be precise and if the parts with low quality would be in use the contact of the valve might get leak after a while due to the high thermal stress and multiple impacts, whereby the automotive would exert from suitable filergiri conditions. Low noise valve, reducing engine efficiency and power, increasing fuel consumption and increasing emissions refer to signs of valve mal-adjustment and inappropriate function conditions of valves that an attempt should be made for proper filergiri. With regard to the sensitivity of this part and its positive effect on optimal performance and reduced engine noise, it is suggested to measure the effect of unadjusted valve filer on the amount of pollutant emissions about Spark ignition engines with E-gas (Stansf ield et al., 2007).

Hydraulic tappet: it is in an abundant use in today's modern engines and the engine works with low noise due to a zeroing amount of valve filer at any moment and condition. This part functions in the hydraulic form that is the oil enters into tappet through the hydraulic pump and main channel which continues along engine while the valve is closed and enters into the back of plunger by moving shotgun and fills the existing air gap at the back of the valve (Leone et al., 1996).

Automotive problems: nowadays, high production of vehicles and consecutively the emissions of toxic gases, global warming have red-alert to us and thus the controls are exercised on them directly or indirectly by the global community. Vehicle exhaust gases which play an important role in the pollution of Earth's atmosphere could be divided into three general categories (Murata et al., 2006):

1- The inert gases on the environment such as oxygen $\mathrm{O}_{2}$ and watervapor $\mathrm{H}_{2} \mathrm{O}$.

2- Greenhouse gases viz., automotive carbon dioxide $\mathrm{CO}_{2}$. 
3- Toxic gases such as automotive carbon monoxide Co, nitrogen oxides $\mathrm{NOx}$, etc.

In the combustion of gasoline which is a chemical reactor, fuel hydrogen $(\mathrm{H})$ in combination with oxygen $(\mathrm{O})$, produces water vapour $\left(\mathrm{H}_{2} \mathrm{O}\right)$ and automotive carbon fuel $(\mathrm{C})$ in combination with oxygen produce automotive carbon dioxide $\left(\mathrm{CO}_{2}\right)$. Due to the incomplete combustion system, some of the fuel automotive carbons cannot always obtain the necessary oxygen thus produce the toxic gas automotive carbon monoxide (CO). Thus, the amount of automotive carbon monoxide should be minimised so as not to exceed $4 \%$ in the most critical situations at idle speed (Stein et al., 1995).

1- The reduction of energy sources: fuel consumption of automotive could be optimised for using less fuel.

2- Temperature of Earth's atmosphere: fuel burning produces a substantial amount of automotive carbon dioxide which accounts for greenhouse gases thus average earth's atmosphere temperature increases by producing this gas.

3- Quality of local air: in cities, vehicle emissions together with other pollutants play a fatal role in the health of humans and other creatures (Benajes et al., 1996).

Soupape: it is a French word which is used in the original form in our language. Valve is the exact meaning for soupape used as parts to control input channels (air-fuel mixture) and output (smoke) and in general each cylinder has at least one air soupape and a smoke soupape (Murata et al., 2006).

Related works: Lee et al. (2010) examined the impact of hot EGR (exhaust gas recirculation) on a conventional diesel or dual fuel diesel engines via software KIVA. The results indicate that high EGR temperature causes increasing Nitrogen oxides emissions due to peak combustion temperature, but production of Nox pollutant has improved by reducing EGR temperature and adding it to the premixed inside the automotive carburettor or the intake manifold (Kramer \& Phlips, 2002). Patterson et al. (1994) used corrected KIVA code to study the effects of injection pressure and two-stage injection on diesel engine performance parameters and emissions of nitrogen oxides that soot from it. Results indicate that the soot injection increases by reducing pressure (Moro et al., 2001). Pierpont et al. (1995) have made an experimental study on the effect of a multiple injection and recirculation on performance and emissions of a direct injection diesel engine. They have used two injector nozzles at various injection angles and concluded that an optimal multiple injection depends on many parameters such as the delay time between injection pulses and injection angle (Roberts \& Stanglmaier, 1999). Mohebbi et al (2012) in an experimental study examined an effect of various recirculation parameters on combustion and emissions performance indices during use of diesel and biodiesel fuel and their mix. Results indicated that PM reduces to a large extent with cooled EGR (Cairns et al., 2006). Jafarmadar (2014) examined an effect of EGR and thermal insulation of the combustion chamber and displayed that insulation causes improvement in performance parameters.

The introduction of 206 and its power generating system: more than 5 million Peugeot 206 worldwide have been produced and supplied and Iran Khodro Company has been regarded as one of the most important manufacturing bases of this automotive in the world. The latest technological and engineering achievements worldwide have been used in design and production of this automotive and the list of standard equipment of this automotive at various types differs. Peugeot 206 is supplied to market with two engines 1360 and $1587 \mathrm{cc}$ at four levels of equipment with types 2, 3, 5 and 6 . This automotive has a four-cylinder engine with features below:

Table 2. Technical specif ications for Peugeot 206

\begin{tabular}{ll}
\hline Engines & 1.4 liter \\
Engine model & $\mathrm{TU}_{3 \mathrm{~A}}$ \\
Engine $\mathrm{CM}^{3}$ capacity & 1360 \\
The piston displacement & $77 \times 75$ \\
piston diameter (mm) & \\
Max power (hp) & $\mathrm{RPM} 5500 @ 75$ \\
The maximum torque (Nm) & $\mathrm{RPM} 3400 @ 118$ \\
Compression ratio & $9 / 6$ \\
- Fuel & unleaded petrol \\
Catalyst & Yes \\
\hline
\end{tabular}

Auto Pride and power generating system: Pride was designed Japanese firm Mazda by Ford ordering, the parent company. The first generation of this automotive which was produced in 1986-1993 was sold in Japan as the Mazda 121 and in North America by Ford Company as Ford Festiva. This model was produced as the Kia Pride from 1987 to 2000 in South Korea's KIA Motors Corporation and its production line was sold to Saipa in 2001. Saipa Company by creating a series of technical manufacturers in Saipa group and the support of the manufacturers at private sector made attempt to build the Pride Car in the country and supplied it with the names Nasim (Pride hatchback ), Saba ( Pride sedan), Saipa 132, Saipa 131, Saipa 111 and Saipa 141 and vans Pride in Iran. This automotive has four-cylinder engine with specif ications below:

Table 2. Technical specifications for Pride

$\begin{array}{ll}\text { Engines } & 1.3 \text { liter } \\ \text { Engine model } & \text { MisNI } \\ \text { Engine } \mathrm{CM}^{3} \text { capacity } & 1323 \\ \text { The piston displacement } & 71 \mathrm{X} 83 / 6 \\ \text { piston diameter (mm) } & \\ \text { Max power (hp) } & \mathrm{RPM} 5500 @ 62 / 5\end{array}$




$$
\begin{array}{ll}
\text { The maximum torque }(\mathrm{Nm}) & \mathrm{RPM} 2800 @ 103 / 3 \\
\text { Compression ratio } & 9 / 6 \\
\text { Fuel } & \text { unleaded petrol } \\
\text { Catalyst } & \text { Yes }
\end{array}
$$

\section{Effect of filler on various engine speeds:}

Carbon monoxide: due to the reduction in breathing time, volumetric efficiency and lack of oxygen, while increasing engine speed the total percent of $\mathrm{CO}$ also increases. As a result, according to three consecutive points, measured with filler at three different engine speeds, it could be concluded that automotive at idle speed doesn't perform minimum pollution, which could be minimized by increasing the speed to maximum torque speed (280o RPM) and again the values increase by increasing the speed to maximum power.

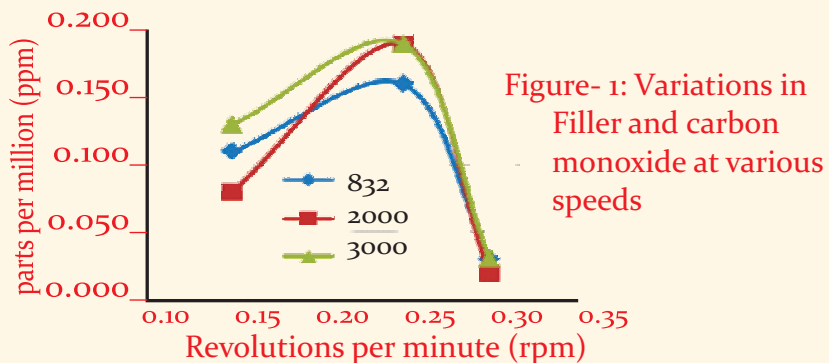

According to the fig.-1, it is observed that amount of produced carbon monoxide in filler 0.3 (idle speed) is greater than 3000 and 2000 . Yet order of pollution at these speeds changes by the change in this amount of filler.

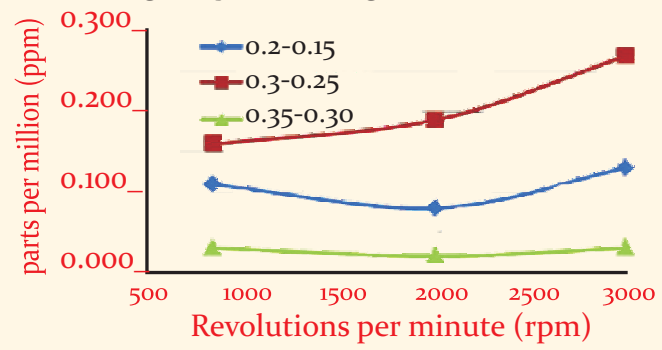

Figure-2: Variations agaisnt engine speed and carbon monoxide at various fillers

Hydrocarbons: according to unburned hydrocarbons curve in terms of engine speed, it could be seen that the fuel injection time has been high at idle speed due to overcoming the initial inertia and acceleration of vehicles. Further, a number of unburned hydrocarbons have been high which could be reduced by warming and accelerating the fuel consumption.

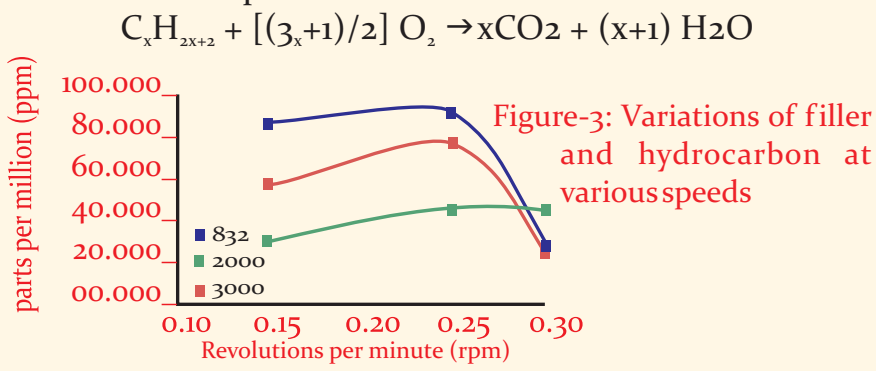

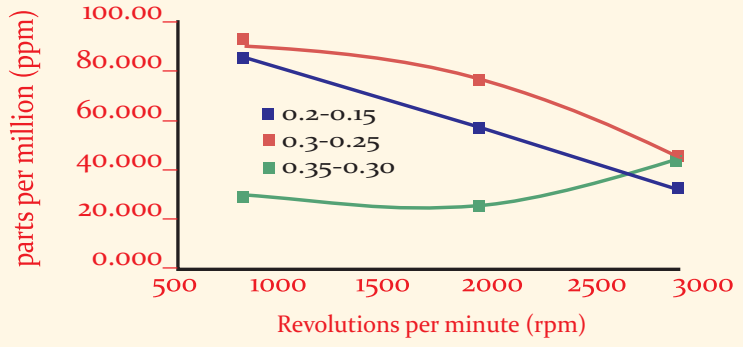

Figure- 4: Varioations of Hydrocarbon and engine speed at various fillers

Carbon dioxide: oxidation of carbon monoxide converts to carbon dioxide. Carbon monoxide is a colourless and odourless toxic gas which damages the human health and nature, whereas carbon dioxide is necessary for photosynthesis. According to fig.-2, the amount of carbon dioxide increases by increasing engine speed.

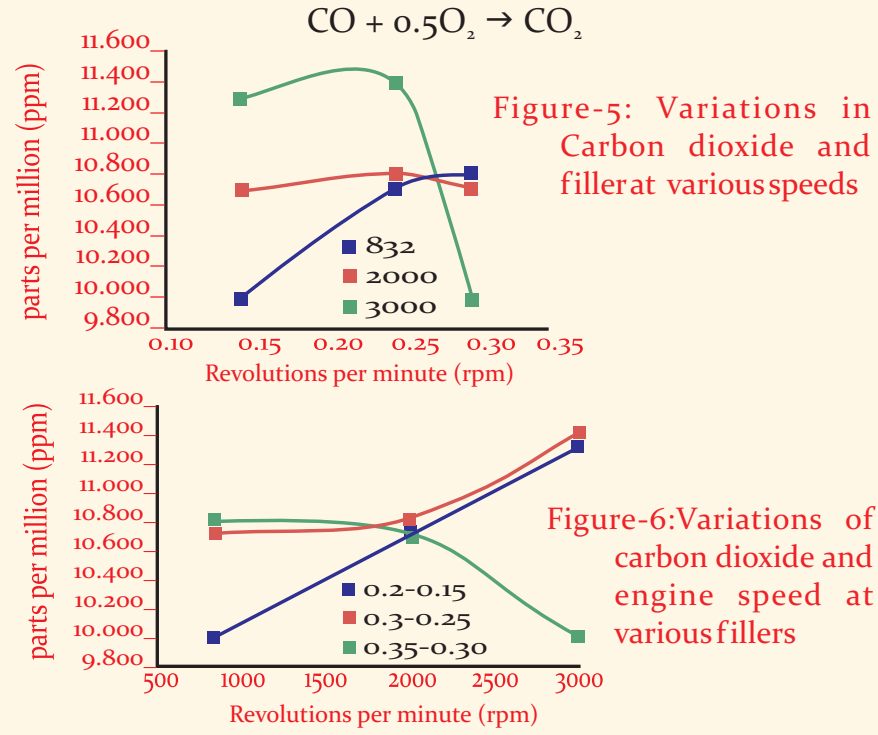

Oxygen: beside the elimination of some harmful fumigation, the harmful gases like nitrogen oxides and $\mathrm{SO}$ also produce some oxygen which is used in $\mathrm{CO}$ to $\mathrm{CO}_{2}$ conversion cycle and a part is used to produce $\mathrm{H}_{2} \mathrm{O}$.
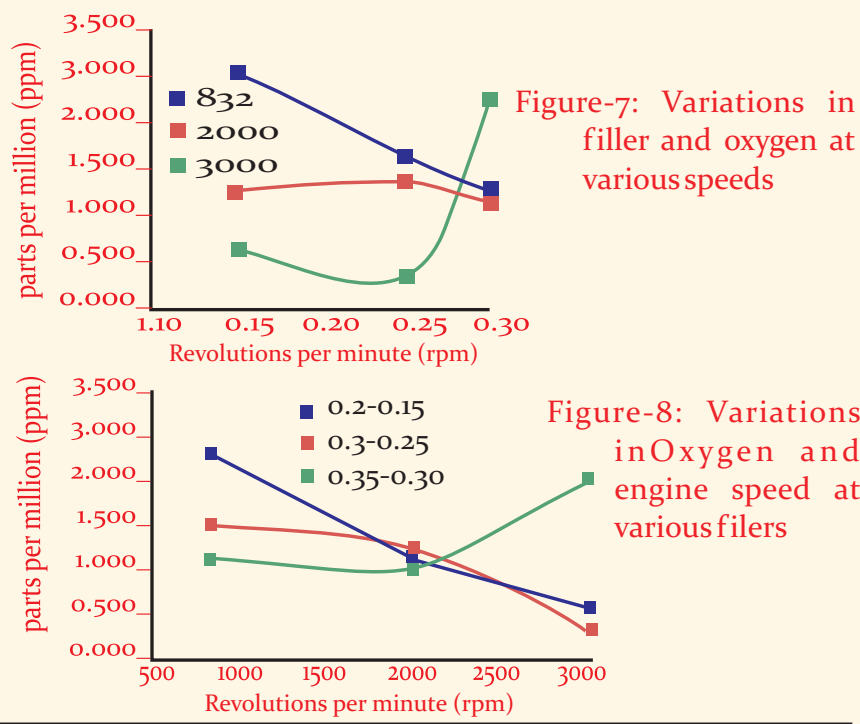

Ambient Science (2017)

http://www.caves.res.in/

Vol.-04(1):p. 36 
Nitrous oxide: nitrogen oxides raise nitrogen in the air due to the excess temperature at combustion chamber, chamber pressure, air-fuel ratio, and ignition timing in the cylinder. With increasing engine speed, NOx increases. NOx emissions are negligent at idle engine speed, NOX slope is steep in the state without the catalyst which Nitrogen oxides turn to nitrogen and oxygen after oxidation and reduce by reaching to ratio 14.7 and then increase.
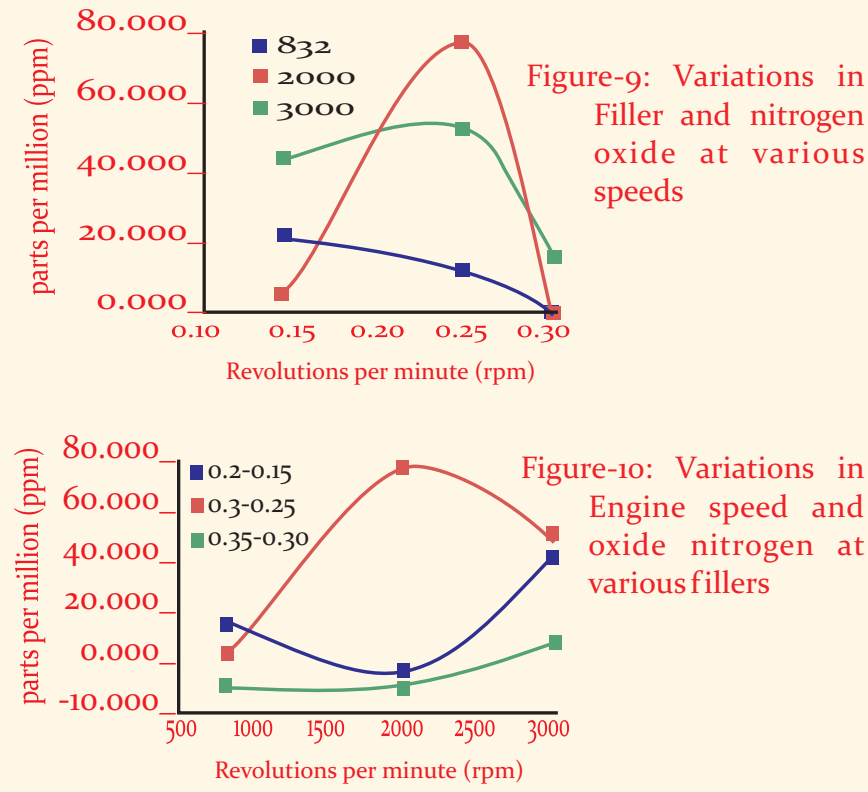

\section{Conclusion:}

Control over high production of automobiles, vehicle emissions as well as to maintain the average earth temperature are one of the major concern in today's urban life. Automobiles emissions play a major role to create pollutions in the cities. Combustion process releases fuel energy. Fuel has been developed from carbon and hydrogen and converted to $\mathrm{H}_{2} \mathrm{O}, \mathrm{CO}_{2}$ and heat under ideal conditions. Our study strengthened the fact that the total combustion never takes place and short combustion time and constant change in fuel ratio, air temperature and chamber conditions of combustion cause variations in the amount of emissions.

Acknowledgements:

We are grateful to the Department of Mechanical Engineering, Jolfa International Branch, Islamic Azad University, Jolfa, Iran which assisted us to conduct this research.

\section{References:}

AAllen, J. \& Law, D. (2001): Advanced combustion using a lotus active valve train: internal exhaust gas recirculation promoted auto-ignition. In: Proceedings of the IFP international congress; 2001. p. 85-100.

Benajes, J., Reyes, E. \& Luj_an, J. (1996): Intake valve pre-lift effect on the performance of a turbocharged diesel engine. $\underline{S A E}$ paper 960950.
Cairns, A., Irlam, G. \& Blaxill, H. (2006): Exhaust gas recirculation for improved part and full load fuel economy in a turbocharged gasoline engine. SAE paper no. 2006-01- 0047.

Heywood, J.B. (1988): Internal Combustion Engine Fundamentals. Pub. by-McGraw-Hill, New York.

Jafarmadar, S. (2014): Multidimensional modeling of the effect of EGR (exhaust gas recirculation) mass fraction on exergy terms in an indirect injection diesel engine. Energy, 66(C):305-313

Kramer U. \& Phlips P. (2002): Phasing strategy for an engine with twin variable cam timing. SAE Technical Paper 2002-01-1101.

Lee K-J, Huyng, T.C. \& Lee, J.T. (2010): A study on realization of high performance without back?re ina hydrogen-fueled engine with external mixture. Int. J. Hydrogen Energ., 35(1): 13078-13087.

Leone, T.G., Christenson, E.J. \& Stein, R.A. (1996): Comparison of variable camshaft timing strategies at part load. $S A E$ paper 960584

Mohebbi, V., Naderifar, A., Behbahani, R.M. \& Moshfeghian, M. (2012): Investigation of Kinetics of Methane Hydrate Formation during Isobaric and Isochoric Processes in an Agitated Reactor. Chem. Eng. Sci., 76:58-65.

Moro, D., Minelli, G. \& Serra, G. (2001): Thermodynamic analysis of variable valve timing influence on SI engine efficiency. SAEpaper no. 2001-01-0667;2001.

Murata, Y., Kusaka, J., Odaka, M., Daisho, Y., Kawano, D, Suzuki H, Kawano. D., Suzuki, H, Ishii, H. \& Goto, Y. (2006): Achievement of medium engine speed and load premixed diesel combustion with variable valve timing. SAE paper 2006-01-0203.

Niglisch, H. \& Helie, J. (2007): Unthrottled engine operation using variable valve actuation: the impact on the flow field, mixing and combustion. SAE paper no. 2007-01-1414; 2007.

Pierpont, D.A., Montgomery, D.T. \& Reitz, R.D. (1995): Reducing particulate and NOx using multiple injections and EGR in a D. I. diesel.SAE paper no. 950217

Roberts, C.E. \& Stanglmaier, R.H. (1999): Investigation of intake timing effects on the cold start behaviour of a spark ignition engine. SAE paper no. 1999-01-3622.

Stansfield, P.A., Wigley, G., Garner, C.P., Patel, R., Ladommatos, N., Pitcher G, Turner, J.W.G., Stein, R.A., Galietti, K.M. \& Leone, T.G. (1995): Dual equal VCT e a variable camshaft timing strategy for improved fuel economy and emissions. SAE paper no. 950975 .

Stansfield, P., Wigley, G., Justham, T., Catto, J. \& Pitcher, G. (2007). PIV analysis of in-cylinder flow structures over a range of realistic engine speeds. L. Exp. Fluids 43:135-146.

Stein, R.A., Galietti, K.M. \& Leone, T.G., 1995. Dual Equal VCT—A Variable Camshaft Timing Strategy for Improved Fuel Economyand Emissions. SAE Paper no. 950975.

Stone R. (1999): Introduction to internal combustion engines, 3rd ed. Basingstoke: Macmillan Press Ltd. 